\title{
LA CULTURA HISTÓRICA. UNA APROXIMACIÓN DIFERENTE A LA MEMORIA COLECTIVA
}

\author{
Fernando Sánchez Costa
}

\section{La desaparición del pasado y la eclosión de la memoria}

Durante siglos, el pasado formó parte del presente y del futuro de los hombres. Pensemos, por ejemplo, en los campesinos de las sociedades pre-industriales. Sus vidas se insertaban en unos marcos estables de larga duración. El campesino del siglo V, o XVII, sabía que pisaría los mismos parajes que habían trillado sus antecesores, que sembraría igual que ellos habían hecho, que utilizaría herramientas semejantes y que participaría en ceremonias religiosas parecidas. Vivía inmerso en la tradición, consciente de que compartía un mundo similar al que habían vivido sus abuelos y al que vivirían sus nietos. Como ha apuntado Pierre Nora, los habitantes de las sociedades rurales no necesitaban realizar un esfuerzo extraordinario para acceder al pasado. Vivían en «milieux de mémoire» ${ }^{1}$ (contextos o ambientes de memoria), donde el pasado era el marco en el que se desarrollaba el presente y en el que se inscribiría el futuro.

Este tiempo lento de la historia empezó a verse decisivamente superado a lo largo del siglo XVIII. Las revoluciones científica, política y tecnológica imprimieron un nuevo ritmo a la Historia. El nuevo paradigma histórico se consolidó durante el siglo XIX. El progreso y el cambio se convirtieron en la bandera del siglo y en una experiencia histórica compartida. Los campesinos migraban a las ciudades, los inventos tecnológicos proliferaban, las revoluciones políticas se sucedían y los medios de comunicación difundían una nueva concepción del tiempo y del espacio. Como ha sintetizado Koselleck, los «espacios de expe-

1. Cfr. Nora, Pierre, Les lieux de mémoire, París, 1984. 
riencia» y los «horizontes de espera», que hasta entonces habían sido similares, comenzaron a distanciarse ${ }^{2}$. Los ciudadanos del siglo XIX, y más todavía los del XX, sabían que el futuro sería diferente del pasado. La experiencia pasada no servía ya para pintar los imaginarios del futuro. La Modernidad Ilustrada y la Revolución Industrial posibilitaron, por tanto, un nuevo régimen de historicidad $^{3}$, una nueva noción del tiempo histórico, caracterizada por la ruptura con el pasado, la idea de progreso y la amplitud de los horizontes de espera inmediatos.

Así, al despertar el siglo XXI, el pasado se ausenta progresivamente del presente. La brecha entre los siglos, entre las décadas, es cada vez mayor. Ya a principios del siglo pasado apuntaba Ortega que la «disociación de pretérito y presente es el hecho general de nuestra época $»^{4}$. La mentalidad moderna no temía, sin embargo, la aceleración de la Historia. Confiaba en la plenitud del futuro y asentaba su vida y su identidad en el mismo. Pero las tragedias del siglo XX y la crisis de las grandes narrativas han truncado la certeza y el optimismo ilustrado. El hombre posmoderno se percata de que la Historia avanza a gran velocidad, pero no sabe exactamente hacia dónde. Algunos historiadores han sugerido que precisamente es la fragilidad del presente y la incertidumbre del futuro lo que ha producido la eclosión del interés social por la memoria ${ }^{5}$. En efecto, el pasado es el único lugar estable y seguro, que ya no está sujeto a los vaivenes del cambio. Ante el vértigo producido por la aceleración de la Historia, nos agarramos al pasado como uno de los últimos asideros posibles. ${ }^{6}$ Así, el pasado, que desaparece progresivamente como latencia, reaparece como memoria. Ya que no podemos vivir «en el pasado» porque la aceleración histórica nos aleja de él, procuramos retenerlo en forma de memoria, de recuerdo, de historia. El pasado, que ya no forma parte de nuestra experiencia cotidiana, es, sin embargo, un anclaje seguro en el que podemos amarrar nuestra tambaleante identidad social.

2. Koselleck, Reinhart, «Time and History», in Koselleck (ed.), The Practice of Conceptual History. Timing History, Spacing Concepts, Stanford University Press, 2002, pp. 100-114. Para Koselleck, la «aceleración de la historia consiste precisamente en el hecho de que los cambios se suceden cada vez con un intervalo temporal menor y, por tanto, los horizontes de espera del futuro próximo se amplían enormemente. Las transformaciones políticas, sociales y económicas no se perciben ya como una posibilidad remota y lejana sino como una certeza cercana, casi inmediata».

3. Cfr. Hartog, François, Régimes d'historicité. Présentisme et expériences du temps, París, 2003.

4. Ortega y Gasset, José, La rebelión de las masas, Madrid, 1966, p. 55.

5. Cfr. Huyssen, Andreas, En busca del futuro perdido. Cultura y memoria en tiempos de globalización, México D.F., 2002, pp. 13-40.

6. Cfr. Traverso, Enzo, El pasado. Instrucciones de uso, Madrid, 2007, p. 16. 
La sensación de ruptura no es, sin embargo, la única característica de la cultura de memoria contemporánea. Siguiendo a la historiadora alemana Aleida Assman, pueden indicarse tres motivos fundamentales por los que nuestra sociedad se asoma a la Historia. Se trata de una triple razón identitaria, lúdicocognitiva y ética ${ }^{7}$. En efecto, la actual aproximación al pasado tiene un tono claramente identitario. En un mundo en constante transformación, fragmentado y relativo, las conciencias identitarias encuentran en la Historia un pavimento firme donde fundamentarse. Acudimos a la Historia para hallar nuestras raíces y nuestras razones, para encontrar un hilo coherente y estable de nuestra identidad individual y social. La aceleración del mundo contemporáneo ha acentuado, sin duda, esta tendencia. Pero, más allá, se trata de una pulsión humana basada en nuestra propia realidad antropológica. Como ha apuntado magistralmente Paul Ricoeur, el ser humano es un ser narrativo ${ }^{8}$, cuya identidad se concreta y se despliega en el tiempo. El modo concreto del ser humano de cada individuo y de cada sociedad se precisa en la Historia. Para entenderse, por tanto, las personas necesitan conocer su historia. Más aún, necesitan contar su historia, narrarla. Sólo a través del relato histórico podemos hilvanar coherentemente la complejidad de nuestra existencia, enlazar de forma inteligible y unitaria la pluralidad de nuestro pasado, presente y futuro.

También acudimos a la Historia en búsqueda de distracción y entretenimiento. La Historia tiene una dimensión lúdica. En las estanterías de las librerías se multiplican las novelas históricas y en las carteleras triunfan las películas de temática histórica. En ocasiones, las películas y las novelas simplemente se ambientan en el pasado. Otras veces, cuentan historias cercanas a la realidad histórica. En efecto, no pocas veces la realidad supera a la ficción en interés y dramatismo. La Historia nos permite trascender las limitaciones del presente, muchas veces anodino o difícil, y vivir otras vidas y otras situaciones. Al igual que la Literatura ${ }^{9}$, la Historia nos ofrece la posibilidad de explorar la condición humana, de revestirnos de otras existencias y viajar en el tiempo y el espacio. La conciencia histórica supone siempre un enriquecimiento personal ${ }^{10}$, ya que nos adentra en otros planos y dimensiones de la realidad (nos ofrece una terce-

7. Cfr. Assmann, Aleida, Geschichte im Gedächtnis: Von der individuellen Erfahrung zur öffentlichen Inszenierung, Munich, 2007, pp. 25-27.

8. Cfr. Ricoeur, Paul, «Life in Quest of Narrative», en Wood, D. (ed.), On Paul Ricoeur. Narrative and Interpretation, New York, 1991, pp. 20-33.

9. Cfr. Kundera, Milan, El arte de la novela, Barcelona, 2000, pp. 13-30.

10. Cfr. Lowenthal, David, The Past is a Foreign Country, Cambridge University Press, 2006, p. 47. Lowenthal cita un pasaje iluminador de Victoria Wolf en su novela Moments of Being: «The present when backed by the past is a thousand times deeper than the present when it presses so close that you can feel nothing else». 
ra dimensión, histórica, que subyace en toda realidad presente). El aprendizaje cognitivo y erudito de la Historia -que predominó en el siglo XIX como parte de la Bildung personal- se mantiene también vigente en nuestra sociedad, aunque hoy acostumbran a preferirse aproximaciones más vivenciales al pasado.

Finalmente, recuperamos el pasado con un doble sentido ético. Siguiendo la célebre sentencia ciceroniana, la Historia ha sido considerada a lo largo de los siglos una sabia educadora, una maestra de vida. "Gran maestro de Príncipes es el tiempo», concluía Saavedra Fajardo en el siglo XVII. ${ }^{11}$ Pero a partir de la posguerra europea, a esta dimensión ejemplificante de la Historia se le ha añadido una nueva función ética de alcance social. Desde entonces, la Historia no es sólo una posibilidad formativa y culta de las élites, sino que ha devenido un deber social. La conmemoración de eventos trágicos se ha convertido en una obligación moral. En una sociedad secularizada, la memoria parece ser el último homenaje posible a quienes fueron víctimas de la injusticia. Es un último desagravio, una reivindicación postrera para dar un mínimo sentido a la tragedia del sufrimiento inocente. El recuerdo del mal pasado se entiende como un antídoto para prevenir su repetición en el futuro.

\section{Los estudios de memoria colectiva y sus límites}

A finales del siglo XIX, el funcionamiento de la memoria había despertado el interés de psicólogos, filósofos y literatos. Freud, Bergson y Proust, entre otros, se habían adentrado, desde sus múltiples disciplinas, en «el gran salón de la memoria» ${ }^{12}$. En 1925, el sociólogo francés Maurice Halbwachs publicó Los cuadros sociales de la memoria, que proponía un giro copernicano en la aproximación a la memoria. Halbwachs sugería que no existe una memoria individual per se. Para Halbwachs, las memorias personales están decisivamente condicionadas por el contexto social y lingüístico en que emergen. La memoria humana no retiene el pasado, sino que lo reconstruye desde el presente gracias a sus vestigios y a la comunicación social. La memoria del sujeto depende, por tanto, de lo que otros le cuentan sobre el pasado, de los discursos y recursos memorísticos que en un determinado momento prevalecen en la sociedad.

11. Los tratadistas políticos del Renacimiento y el Barroco encarecían la educación del Príncipe heredero a través de la Historia. La Historia debía revelarle los misterios del comportamiento humano y le permitiría proseguir los aciertos del pasado y evitar sus errores. «Por lo cual es menester que busque el príncipe (....) los libros de historia, que ni adulan, ni callan, ni disimulan la verdad (...) Conocidos bien estos dos tiempos, pasado y presente, conocerá también V. A. el futuro; porque ninguna cosa nueva debajo del sol. Lo que es, fue. Y lo que fue, será. Múdanse las personas, no las escenas». SAAvedra FAJARDo, Diego, Idea de un príncipe políticocristiano representado en cien empresas, Empresa 28, Biblioteca Virtual Miguel de Cervantes.

12. Agustín de Hipona, Confesiones, Libro V, Capítulo VIII, 14. 
Tras varios decenios notablemente olvidado, Halbwachs fue redescubierto a principios de la década de 1980, en un contexto de renovado interés por la memoria social. Desde entonces, el debate sobre la memoria colectiva no ha hecho más que crecer. Se han publicado centenares de estudios, se han constituido grupos de investigación, se han aprobado leyes de memoria pública. ¿A qué se debe este repentino y creciente interés académico por la memoria colectiva?

Apuntaré brevemente tres razones. En primer lugar, a finales de los años 60 empezó a reivindicarse el recuerdo de las atrocidades de la II Guerra Mundial como una obligación ética. Imbuidas del pensamiento crítico de resonancias marxistas, la generación alemana de la posguerra tomó como uno de sus leitmotiv el distanciamiento del nazismo y, más aún, la denuncia de la connivencia mostrada por las generaciones pasadas. Los crímenes no debían olvidarse, sino denunciarse para evitar su repetición en el futuro. Con el paso de los años, por otro lado, la progresiva desaparición de los supervivientes de los campos de exterminio ha suscitado el debate sobre cómo mantener vivo el recuerdo de la tragedia una vez que sus sufrientes han desaparecido (memoria post-testimonial).

El segundo motivo del interés académico por la memoria debe situarse en el giro culturalista en los ambientes intelectuales a partir de la década de 1970. Los modelos estructuralistas y socioeconómicos que habían dominado las Ciencias Sociales desde la posguerra fueron progresivamente desplazados por una aproximación más antropológica y cultural a las ciencias humanas. La nueva perspectiva acentuaba los discursos y las representaciones culturales por encima de las estructuras económicas y las condiciones materiales. Sobre este humus conceptual florecieron los estudios alrededor de la identidad, que acabaron favoreciendo el interés por la memoria social, entendida como un discurso compartido que influye decisivamente en la identidad del grupo.

El tercer motivo de la eclosión de los estudios sobre la memoria colectiva es el cariz político que este asunto ha tomado en diversos países. El debate sobre la memoria histórica se ha convertido en un verdadero catalizar de las discusiones sobre el presente y el futuro nacional. Especialmente en países sometidos a dictaduras, la reivindicación de la memoria histórica se ha erigido en un símbolo de lucha contra los valores que las dictaduras encarnaron y en un acto de reparación y justicia postrera.

El debate sobre la memoria colectiva ha encontrado un notable eco en la esfera pública y ha concertado la intervención de testigos, historiadores, políticos y periodistas. Todo ello ha provocado, sin embargo, una cierta confusión. Se habla constantemente de memoria colectiva pero no se acaba de saber exactamente en qué consiste. Es un concepto poderoso, de fuertes resonancias polémicas y sentimentales. Un concepto, por tanto, adecuado para el uso mediático y po- 
lítico. Pero diversos historiadores y sociólogos se han percatado últimamente que el interés que gana por su fuerza lo pierde por su imprecisión. Sintetizaré, a continuación, algunas de las objeciones principales al concepto de memoria colectiva.

La crítica más antigua y persistente radica en que la memoria colectiva, como tal, no puede existir. Se trata de una entelequia. En efecto, la memoria exige siempre un sujeto recordante. No subsiste por sí misma sino siempre en un sujeto que recuerda. Ahora bien, ies la colectividad un sujeto capaz de memoria? La sociedad, como tal, no es un sujeto con capacidades cognitivas o con pensamiento propio y, por tanto, no puede tener una memoria. Por otro lado, se ha reprochado a los estudios de memoria colectiva una concepción excesivamente ontológica de la memoria colectiva, en la que ésta se imagina como un conjunto de ideas platónicas que sobrevuelan la comunidad.

Los autores que tratan la memoria colectiva no han permanecido ajenos a estas críticas. En muchos casos, ellos mismos les han dado voz. Han presentado y discutido las objeciones y han procurado resolverlas proponiendo una noción de memoria colectiva lejana de idealismos platónicos. Para el teórico de la Historia Reinhart Koselleck, por ejemplo, no es correcto hablar de memoria colectiva sino de condiciones colectivas de la memoria ${ }^{13}$. Una conclusión similar obtiene el psicólogo social Barlett, que reclama pasar de la memoria del grupo a la memoria en el grupo. ${ }^{14}$ Zerubavel y Lebow acentúan el hecho de que la estructura de la memoria individual está moldeada por los esquemas sociales. Según Zerubavel, «remembering is also governed by unmistakably social norms of remembrance» ${ }^{15}$; para Below, «one's ability to store, recall, and reconfigure verbal and nonverbal stimuli is mediated by patterns learned from one's personal and cultural environments». ${ }^{16}$

Las conclusiones a las que llegan los autores son bastante similares. Todos ellos insisten en la mediación social que precede y posibilita toda memoria individual. Tanto la forma como buena parte del contenido de la memoria individual son modelados socialmente, es decir, a través de la comunicación y la enseñanza. El centro de la memoria colectiva parece estar, por tanto, en el proceso comuni-

13. Koselleck, cit. en Shönnemann, Bernd, Geschichtskultur als Wiederholungsstruktur?, Conferencia pronunciada en la Westfälischen Wilhelms-Universität Münster, 2006.

14. Wertsch, James V., Voices of Collective Remembering, Cambridge University Press, 2007, p. 22.

15. Zerubavel, Eviatar, Time Maps. Collective Memory and the Social Shape of the Past, Chicago, 2003, p. 3.

16. Lebow, R.N., «The Memory of Politics in Postwar Europe», en Lebow, R. N., Kansteiner, W. y Fogu, C. (eds.), The Politics of Memory in Postwar Europe, Duke University Press, 2006, p. 9. 
cativo. Según Aleida Assmann, cuando Halbwachs habla de memoria colectiva se refiere a «una memoria social que no procede de una participación mística, sino que sólo se produce a través del relato, del intercambio actual y comunicativo». ${ }^{17}$ Lebow ha insistido en que a través de este intercambio comunicativo entre personas se difunden los discursos dominantes en la sociedad y ha remarcado la relación entre discurso (de memoria) y poder político: «those discourses and their content, in turn, are generally created by elites and counter-elites to justify themselves and to advance their political, economic, and social goals». ${ }^{18}$

Sin embargo, los estudios de memoria colectiva han sido criticados también por otros motivos. Uno de ellos es la habitual utilización de categorías psicológicas para explicar los procesos de la memoria colectiva. En 2002 apareció en la revista History and Theory un artículo de Wulf Kansteiner titulado «Finding Meaning in History: A Methodological Critique of Collective Memory Studies». El académico americano reprobaba los estudios comunes sobre la memoria colectiva por haber aplicado acríticamente una analogía injustificada entre el funcionamiento de la memoria individual y la memoria colectiva. Kansteiner criticaba la utilización de categorías psicoanalíticas (represión, trauma, etc.) en el estudio de la memoria social. El autor concluía que la memoria individual y la discusión pública sobre el pasado siguen dinámicas distintas y, por tanto, es erróneo emplear términos psicoanalíticos para auscultar la memoria colectiva ${ }^{19}$.

La tercera objeción a los estudios sobre la memoria colectiva reside en que han centrado habitualmente su atención en los productores de los discursos de memoria y en sus contenidos, pero han tendido a olvidar los medios utilizados en su difusión y, más todavía, su recepción ${ }^{20}$. De este modo, se han investigado las políticas de memoria y sus mensajes, pero se ha omitido su repercusión, tendiendo así a confundir las narrativas de las élites con la memoria compartida por la ciudadanía. Ha habido ya algunos autores, sin embargo, que han situado los medios o soportes de la memoria (con sus mensajes parejos) en el epicentro de sus estudios. Éste es el caso de Jan Assmann, quien publicó en 1992 un conocido libro sobre la «memoria cultural». El historiador alemán señala que la «memoria fundante» de toda civilización se transmite a través de un cuerpo de textos e imágenes, a los que denomina «memoria cultural $»^{21}$. El mismo año en que Kans-

17 Assmann, Aleida, Der lange Schatten der Vergangenheit, Múnich, 2006, p. 29.

18 Lebow, R. N., «The Memory of Politics in Postwar Europe», p. 4.

19 Kansteiner, Wulf, «Finding Meaning in Memory: a Methodological Critique of Collective Memory Studies», History and Theory, (May 2002), pp. 179-197.

20 Ibid., p. 180.

21. Assmann, Jan, Das kulturelle Gedächtnis. Schrift, Erinnerung und politische Identität in frühen Hochkulturen, Munich, 1992. 
teiner publicaba su crítica a la metodología de los estudios sobre la memoria, el historiador americano James Wertsch publicó un jugoso libro sobre la memoria colectiva en Rusia, al que tituló Voices of Collective Remembering. Wertsch analiza la memoria social desde la perspectiva del «análisis sociocultural», cuyos principios metodológicos parten de los postulados teóricos de los académicos rusos Vygotsky, Luria y Bakhtin ${ }^{22}$. Para Wertsch, el ser humano es un «ser capaz de utilizar herramientas culturales». En este sentido, la memoria colectiva reside en que una determinada comunidad comparte unas mismas herramientas del recuerdo, es decir, unos mismos textos y unas mismas narrativas. Forman una comunidad mnemónica porque son una comunidad textual. ${ }^{23}$

Finalmente, puede argüirse que el concepto de «memoria» tiene un carácter excesivamente subjetivista. Ello significa, en primer lugar, que la memoria es, por naturaleza, personal y, por tanto, el concepto de memoria colectiva es algo forzado. Este subjetivismo implica, en segundo lugar, que la memoria no puede ser sometida a crítica. Por definición, la memoria es el recuerdo de una vivencia. No se le puede achacar a nadie que su memoria sea errónea. En efecto, puede ser que no se corresponda con la realidad objetiva de los hechos, pero ¿no es acaso la memoria el recuerdo de la experiencia subjetiva de los mismos?

\section{Conciencia histórica y cultura histórica}

La memoria colectiva es una categoría de análisis con un notable poder evocador y una indudable dimensión política y mediática. Se trata de un concepto que ha abierto muchos caminos en la investigación histórica y ha producido buenos resultados. Pero hemos constatado también que presenta algunas dificultades conceptuales significativas y su utilización política y mediática ha dificultado un uso neutro y riguroso del mismo. Por ello, creo oportuno dar a conocer, en las próximas páginas, una perspectiva algo diferente sobre la memoria social. Se trata de una aproximación teórica y práctica nacida en el ámbito de la historiografía germánica. Me refiero al concepto de «cultura histórica» (Geschichtskultur) ${ }^{24}$. Pienso que las bases teóricas que han sentado los promotores de este concepto y

22. Wertsch, James, Voices of Collective Remembering..., pp. 10-30.

23. «Insted of positing the vague mnemonic agency that is a thread running through the members of a group, the idea is that they share a representation of the past because they share textual resources. The use of this text may result in homogeneus, complementary, or contested collective memory, but in all cases, it is the key to understanding how distribution is possible». Wertsch, James, Voices of Collective Remembering..., p. 26.

24. El concepto de cultura histórica fue propuesto ampliamente y teorizado por primera vez por Jörn Rüsen. Cfr. Rüsen, Jörn, «Was ist Geschichtskultur? Überlegungen zu einer neuen Art, über Geschichte nachzudenken», en Fübmann, K., Grütter, H. y Rüsen, J. (eds), Historische Faszination. Geschichtskultur heute, Colonia, 1994, pp. 3-26. 
la metodología que puede desprenderse de ellas, puede contribuir a objetivar el debate sobre la memoria colectiva y puede ofrecer a los historiadores una clave hermenéutica bien trabada para analizar las múltiples relaciones que las sociedades establecen con su pasado.

El concepto de cultura histórica se gestó en el marco de una reflexión multidisciplinar sobre la conciencia histórica y la didáctica de la Historia. A partir de la década de 1970, un grupo de historiadores empezó a indagar qué factores sociales intervenían en la configuración de la conciencia histórica de los ciudadanos y, al mismo tiempo, cómo esta conciencia se plasmaba y se objetivaba después en el espacio público. ${ }^{25}$ La noción de conciencia histórica se encuentra, pues, en la base del armazón teórico que sostiene el concepto de cultura histórica y merece la pena precisar brevemente qué debemos entender por conciencia histórica. ${ }^{26}$

Jörn Rüsen ha definido la conciencia histórica como la actividad cognitiva basada en la memoria que nos permite orientarnos en el tiempo y darle sentido. «Historical consciousness includes the mental operations (emotional and cognitive, conscious and unconscious), through which experienced time in the form of memory is used as a means of orientation in everyday life». ${ }^{27}$

La vida del ser humano tiene una estructura temporal. La persona se conjuga en el tiempo. Su personalidad y su identidad se precisan a lo largo de una historia. Esta historia incluye los estratos del pasado, las vivencias del presente y las expectativas del futuro. Puede decirse que una persona tiene conciencia histórica cuando se percata de la estructura temporal de su existencia, cuando es consciente de que su pasado condiciona su presente y el presente marcará su futuro. Gracias a la conciencia histórica, el sujeto puede descubrir la consistencia de su identidad. Es decir, el sujeto logra entender que es fruto de su historia ${ }^{28}$ pero, al

25. Sobre la génesis del concepto de cultura histórica, cfr. Schöneman, Bernd, «Geschichtsdidaktik, Geschichtskultur, Geschichtswissenschaft», en Günther-Arndt, H., Geschichtsdidaktik. Praxishandbuch für die Sekundarstufe I und II, Berlin, 2003, pp. 11-22.

26. La relación entre conciencia histórica y cultura histórica queda patente en las definiciones que los teorizadores de la cultura histórica ofrecen de la misma. Para Rüsen, «la cultura histórica es la articulación práctica y operante de la conciencia histórica en la vida de una sociedad». (Rüsen, Jorn, «Was ist Geschichtskultur?», p. 10). Para Schöneman, la conciencia histórica y la cultura histórica son dos caras de la misma moneda: la cultura histórica es la cara exterior o visible de la cara interior que es la conciencia histórica. (SCHÖNEMAN, Bernd, «Geschichtsdidaktik, Geschichtskultur, Geschichtswissenschaft», p. 18.).

27. Rüsen, Jörn, «What is Historical Consciousness? - A Theoretical Approach to Empirical Evidence». Comunicación presentada en el Congreso «Canadian Historical Consciousness in an International Context: Theoretical Frameworks», Vancouver, University of British Columbia, 2001, p. 2.

28. Ello no lo arroja al determinismo, sino al contrario, a la conciencia de su libertad. 
mismo tiempo, la trasciende, en cuanto que a través de los cambios él siempre permanece él mismo, aunque no necesariamente el mismo. La conciencia histórica es, por tanto, la aprehensión de la temporalidad, por la que distinguimos entre pasado, presente y futuro y, por tanto, podemos orientarnos en la existencia. El motor de la conciencia histórica es la memoria, que permite el recuerdo y la clasificación temporal de las vivencias.

Pero la conciencia histórica no es simplemente una conciencia formal y vacía de la temporalidad. Incluye el conocimiento de lo que ha sucedido en el tiempo. La conciencia histórica no es simplemente la noción de que el tiempo pasa, sino el conocimiento de que, en ese tiempo que pasa, pasan cosas. Mi conciencia histórica no reside simplemente en saber que yo he ido pasando por distintas edades, sino en saber que durante esas edades sucedieron múltiples hechos que configuran mi realidad actual. Gracias a estas dos dimensiones de la conciencia histórica (que captan la forma y el contenido de la experiencia temporal) podemos orientarnos en el tiempo y dar sentido a la realidad. La realidad tiene un sentido -desde esta perspectiva concreta- porque no es una arbitrariedad, sino que es fruto de un proceso histórico. Mi presente tiene sentido, es explicable, dentro de una trama vital (historia). Pero más todavía, mis acciones tienen sentido porque les otorgo un lugar dentro de un horizonte de futuro (intención). Es decir, mis acciones tienen sentido porque las sitúo en una trama vital que proviene del pasado, subsiste en el presente y se abre hacia el futuro. Sin conciencia histórica viviríamos encerrados en el presente, el mundo sería ininteligible y, por tanto, nuestra condición no diferiría en gran medida de la de los animales.

La conciencia histórica les parece a los adultos algo evidente, pero no lo es tanto. Los niños más pequeños viven inmersos en el presente. Hasta los doce años no logramos empezar a ubicar los hechos históricos en su perspectiva temporal correcta. Tenemos que aprender a historiar la realidad. A ello nos ayuda, sin duda, la sociedad. Con el paso de los años no sólo aprendemos a historiar nuestra vida, sino que también empezamos a situarla en el marco de una historia mucho más amplia, que supera con creces los límites de nuestra experiencia biológica. Gracias a la comunicación y al relato, aprendemos que el bisabuelo, al que nunca conocimos, existió y es causa de nuestra existencia. Aprendemos que hace quinientos años los europeos conquistaron el Nuevo Mundo y, por eso, sus habitantes hablan nuestras lenguas. Aprendemos así a sumergirnos en el pasado, a distender nuestra memoria muy lejos de nuestras propias experiencias y a encontrar el sentido histórico del desarrollo de la humanidad y de nuestra comunidad. El relato y la narrativa hilvanan nuestra vida en un gran tapiz colectivo, del que nos sentimos parte y nos identificamos. Desde entonces, la historia de nuestro grupo es también nuestra historia. 
La conciencia histórica se nutre de los discursos históricos que pueblan una comunidad (familiar, nacional, religiosa). Por su parte, cada individuo comparte y expresa también sus experiencias y memorias. Las memorias (que aportan el contenido de la conciencia histórica) no suelen quedarse encerradas en la conciencia del sujeto. Normalmente, se comunican, se materializan en forma de palabra, de imagen, de objeto. En efecto, sin la materialización, la memoria se desvanecería. Los signos del pasado (los lugares de memoria) son las puertas que nos permiten acceder a los vastos palacios del recuerdo y del pasado. La memoria necesita encarnarse para poder ser conservada, comunicada, compartida. De este modo, la conciencia histórica se objetiva, se hace cultura.

¿Cómo se configura la conciencia histórica de los individuos de una sociedad? Su imagen de la historia se forma, primariamente, en la escuela. En la asignatura de Historia, los niños aprenden el pasado y empiezan a distinguir los distintos períodos históricos. Pero la escuela no es el único lugar en el que niños y adultos conforman su conciencia histórica. Sus representaciones del pasado se forjan también a través de los relatos familiares, los álbumes de fotos, los museos, las novelas históricas, las revistas de Historia, los libros académicos, las series de televisión, etc. La conciencia histórica del sujeto se forma en un humus de conocimiento e interpretación del pasado al que podemos llamar «cultura histórica».

La cultura es el modo en que una sociedad interpreta, transmite y transforma la realidad. La cultura histórica es el modo concreto y peculiar en que una sociedad se relaciona con su pasado. «Historical culture refers to people's relationships to the past at a variety of levels and the manner in which these relationships are articulated in a broad array of narratives, media, ideologies and attitudes ${ }^{29}$. Con la categoría de cultura histórica definimos, por tanto, el conjunto de recursos y prácticas sociales a través de las cuales los miembros de una comunidad interpretan, transmiten, objetivan y transforman su pasado.

Al estudiar la cultura histórica indagamos la elaboración social de la experiencia histórica. Es imposible acceder al pasado en cuanto que pasado. Para aproximarnos a él debemos representarlo, hacerlo presente a través de una reelaboración sintética y creativa. Pero la elaboración de la experiencia histórica y su uso en el presente se enmarca siempre dentro de unas prácticas sociales de interpretación y reproducción de la Historia. La conciencia histórica de cada individuo se teje, pues, en el seno de un sistema socio-comunicativo de interpre-

29. Grever, Maria, «The Gender of Patrimonial Pride», in Wieringa, S. (ed.), Travelling Heritages. New Perspectives on Collecting, Preserving and Sharing Women's History, Amsterdam, 2008, p. 287. 
tación, objetivación y uso público del pasado, es decir, en el seno de una cultura histórica.

La práctica social de transmisión y recuerdo del pasado toma la forma de un sistema o de una red socio-comunicativa (con una organización y una infraestructura propia ${ }^{30}$ ). El análisis comunicativo me parece, por tanto, la clave para entender los procesos por los que se difunde y discute en una sociedad una determinada interpretación de la Historia. En toda acción comunicativa se dan cuatro elementos o agentes principales, que son también la base de la cultura histórica. La acción comunicativa incluye un emisor, un mensaje, un medio y un receptor. El estudio de la cultura histórica, de la elaboración social de la experiencia histórica a través de unas determinadas herramientas culturales, debe atender a estos cuatro factores, que analizaré a continuación.

\section{Agentes y componentes de la cultura histórica}

\section{Configuradores de la cultura histórica}

Si bien son muchas las personas que viven una experiencia histórica determinada, son pocas las que elaboran un discurso sobre la misma y lo proyectan en el espacio público. Hay, pues, unos agentes que son especialmente activos en la difusión de determinadas lecturas del pasado. Son, los que podríamos llamar «configuradores de la cultura histórica».

Debemos preguntarnos, en primer lugar, por qué hay gentes interesadas en promover una memoria compartida, una interpretación concreta de la Historia. Probablemente, las razones son múltiples. No es igual la intención del autor de novelas históricas que la del académico de la Historia. Voy a detenerme, especialmente, en las razones que mueven a los políticos a promover unas determinadas políticas de memoria. A lo largo de este artículo se ha procurado señalar más de una vez la estrecha relación entre memoria e identidad. Sobre la memoria se estabilizan y desestabilizan identidades, se afirman y critican, se cambian o consolidan..$^{31}$ Una de las funciones de la narrativa histórica es delinear los límites de la comunidad. Todo relato histórico distingue entre «nosotros»y «ellos». Al proponer una determinada lectura de la Historia, los dirigentes sociales promue-

30. La historiadora holandesa Maria Grever distingue dos niveles en la cultura histórica: «The concept implies both the production and reproduction of historical knowledge, as all as the social 'infrastructure' of the field of history (e.g., the existence of museums, the content of school history curricula, national holidays and other memorial observances, etc.) -all of which provide the conditions that are necessary for people to deal with the past». (Grever, Maria, «The Gender of Patrimonial Pride», p. 288.).

31. Cfr. Rüsen, Jorn, «Was ist Geschichtskultur», p. 11. 
ven una noción concreta de la comunidad, de sus límites y sus características (de su identidad, en el fondo). De este modo difunden una conciencia identitaria particular, que se decantará posteriormente en unas actitudes políticas concretas. Una visión compartida de la Historia cohesiona decisivamente al grupo. El ensayista francés Ernest Renan lo subrayó a finales del siglo XIX al explicar la naturaleza de la nación: «En el pasado, una herencia común de gloria y dolor; para el futuro, un proyecto común. Haber sufrido, haberse alegrado, haber esperado juntos: ello tiene mucho más valor que unos impuestos y unas fronteras comunes». ${ }^{32}$

El Estado es, actualmente, uno de los principales tejedores de conciencia histórica. Sin embargo, ni en los regímenes más autoritarios ha conseguido el poder político controlar completamente la conciencia histórica de sus ciudadanos ni monopolizar la cultura histórica de la sociedad. Los discursos dominantes hallan siempre contrapuntos en narrativas disonantes y subterráneas, que erosionan los fundamentos de la memoria institucional ${ }^{33} \mathrm{y}$, muchas veces, acaban por imponerse cuando el antiguo marco político-cultural cae ch $^{34}$.

Además del Estado, hay muchos otros agentes que participan en la configuración de las representaciones sociales del pasado. Un grupo destacado es el que forman los profesionales de la Historia. La escuela es una fragua intensiva en la que se ponen los fundamentos de la conciencia histórica de los ciudadanos. La Universidad, más independiente con respecto a las políticas de memoria oficial, es también un telar central en el moldeo de la cultura histórica. La aproximación académica al pasado tiene, habitualmente, unos rasgos peculiares. Se trata de una lectura del pasado menos existencial y más cognitiva, más científica y menos identitaria, más orientada al contenido del pasado en sí mismo que a su uso en el presente. Muchas veces se ha pretendido separar con nitidez la Historia (como ciencia sobre el pasado) de la memoria (como vivencia y recuerdo personal del mismo). Desde la perspectiva que adopto en este artículo, en cambio, Historia y memoria son dos elementos que configuran conjunta, aunque distintamente, la cultura histórica. Son dos aproximaciones válidas e interrelacionadas sobre el

32. Cit. en Assman, Aleida, Der lange Schatten der Vergangenheit, p. 42.

33. Cfr. Aróstegui, Julio, «Retos de la memoria y trabajos de la historia», Pasado y Memoria. Revista de Historia Contemporánea, 3 (2004), pp. 15-36.

34. Jan Assmann ha apuntado acertadamente que, si bien los discursos de memoria sirven habitualmente como báculo del poder, también pueden utilizarse como arma contra el poder establecido. Así, el recuerdo de un pasado mejor al presente puede movilizar a los ciudadanos contra la situación actual y en pos de un cambio político o social. (Assmann, Jan, Das kulturalle Gedächtniss..., p. 79). En todo caso, también este extremo demuestra que la memoria no suele ser neutra, sino que tiene habitualmente una intencionalidad política. 
pasado que conforman de distinto modo y a distinto nivel la conciencia histórica de los miembros de una sociedad.

En nuestra sociedad de la comunicación, los medios de comunicación y los periodistas juegan también un papel destacado en el sistema de la cultura histórica. Los novelistas, los cineastas, los fotógrafos, los guionistas, contribuyen a pintar los imaginarios históricos de los ciudadanos. La familia es también un vector decisivo en la transmisión de recuerdos y relatos sobre el pretérito. También la Iglesia atesora una determinada cultura de memoria que comunica a sus fieles ${ }^{35}$. No es posible señalar ahora todos los agentes que intervienen en este proceso. Pero sí es interesante subrayar que en muchas ocasiones la configuración de la cultura histórica se produce bajo un paraguas institucional. Instituciones como el Estado, la Universidad o la Iglesia se erigen en estructuras permanentes que garantizan la conservación, la elaboración y la difusión de determinados discursos de memoria. ${ }^{36}$

\section{Los medios de la cultura histórica}

Si entendemos la cultura histórica como una dinámica de transmisión y discusión social sobre el pasado, debemos atender y estudiar, sin duda, los medios que posibilitan la interacción de la sociedad con su historia. Habitualmente, los medios no han despertado un especial interés entre los estudiosos de la memoria. Por ello es apropiado recordar de vez en cuando la hiperbólica sentencia de McLuhman: «el medio es el mensaje».

Para Wulf Kansteiner, «memories only assume collective relevance when they are structured, represented and used in a social setting. As a result, the means of representation that facilitate this process provide the best information about the evolution of collective memories $»^{37}$. La cultura histórica adopta y se sirve de diversos formatos. Kansteiner los ha clasificado distinguiendo entre medios discursivos, visuales y espaciales ${ }^{38}$ y ha enfatizado que la cultura histórica se cimienta sobre un "collage multimedia» ${ }^{39}$, en el que se entreveran una rica diversidad de formatos y medios.

Entre los medios textuales, cabe destacar los libros de temática histórica. Entre los más relevantes se cuentan los manuales de texto escolares, que contribuyen decisivamente a moldear la conciencia histórica de los jóvenes. Dado

35. El recuerdo de las palabras divinas y de sus intervenciones en favor de Israel es una constante a lo largo del Antiguo Testamento. La idea de memorial es uno de los ejes de la liturgia judeo-cristiana.

36. Cfr. SCHÖNEMAN, Bernd, «Geschichtskultur als Wiederholungsstruktur?»...

37. Kansteiner, Wulf, «Finding Meaning in Memory», 190.

38. Ibidem.

39. Ibidem. 
que se dirigen a un público con un entendimiento en formación y poco crítico, son objeto de análisis minuciosos y polémicas habituales. Las novelas históricas ocupan también un lugar principal entre los medios escritos. Walter Scott a nivel internacional y Benito Pérez Galdós a nivel nacional, popularizaron en el siglo XIX este género literario que hoy está plenamente consolidado. Como ha recordado Lowenthal, «the most pellucid pearls of historical narrative are often found in fiction, long a major component of historical understanding». ${ }^{40}$

Sin lugar a dudas, la televisión y el cine ostentan una posición privilegiada en la configuración de los imaginarios históricos. La imagen que tenemos del pasado se desprende, en muchas ocasiones, de series televisivas o programas especializados sobre el mismo. El cine ha perfilado muchas de las representaciones históricas hoy generalizadas. La imagen que nuestra sociedad tiene de Roma bebe en mayor medida de películas como Ben-hur y Gladiator que de las ruinas de Tarraco o Mérida. Nuestra representación de la Segunda Guerra Mundial está pintada por filmes de éxito como La lista de Schindler o La vida es bella. Internet juega también un papel creciente en la difusión del conocimiento histórico. De hecho, la red supone una reestructuración importante de los mecanismos tradicionales de la cultura histórica. La red virtual diluye la distinción entre creadores y receptores de cultura histórica, facilitando a todos los ciudadanos una plaza pública para exponer los propios discursos y criticar los ajenos. Internet refuerza la democratización de la cultura histórica, multiplica su pluralidad y ofrece una plataforma en la que pueden combinarse formatos visuales, escritos y sonoros.

Entre los múltiples medios de la cultura histórica, me limitaré finalmente a reseñar algunos que posibilitan la conmemoración pública. El espacio de nuestras ciudades se ha convertido en un escenario del recuerdo. En efecto, la construcción de la nación ha conllevado una amplia resemantización del espacio público ${ }^{41}$. Durante los últimos dos siglos los lugares de paso (las calles) han sido convertidos en lugares de memoria. Los nombres de las calles evocan actualmente personajes y hechos históricos. El nomenclátor de una ciudad traza un curioso tapiz de memoria ${ }^{42}$ y esboza un índice de la historia nacional ${ }^{43}$. A través

40. Para el autor americano, «The historical novel fulfilled two needs. First, it let reader feel the past as formal history could not. (...) Second, fiction put readers in the past like people of the time, who could not know what was coming next». (Lowenthal, David, The past is a foreign country..., pp. 225-226).

41. Azaryarhu, Maoz, «The Power of Commemorative Street Names», en Enviroment and Planning D: Society and Space, volume 14, 1996, p. 321.

42. Cfr. Sánchez Marcos, Fernando y Sánchez Costa, Fernando, «Identities, Memories and Street Names. Historical Memory in the Urban Plan of Barcelona, Lima and Manila», en New Orientations in Historiography: Regional History and Global History, Shanghai, 2009. 43. Cfr. Azaryahu, Maoz, «The Power of Commemorative Street Names». 
de sus nombres, las calles se erigen en vitrinas identitarias en las que pueden observarse los valores y la autorepresentación de la comunidad ${ }^{44}$. En las plazas, se levantan también centenares de estatuas que conmemoran las figuras que la memoria oficial ha canonizado. De este modo, la sociedad celebra su pasado y se celebra en él, proclama sus principios y refuerza su identidad a través de una interpretación común del pasado. Las conmemoraciones urbanas pueden ejercer, al mismo tiempo, de catalizadoras de los desacuerdos sociales sobre el pasado y el presente ${ }^{45}$. Como ha demostrado la Historia Contemporánea de España, los nombres de las calles y los monumentos ofrecen un campo de discusión donde pueden debatirse y confrontarse, a veces apasionadamente, discursos de memoria divergentes y enfrentados. Por otro lado, los cambios de nombres de calles y el derribo de monumentos constituyen un acto de propaganda inmejorable para anunciar un cambio de régimen ${ }^{46}$. Al modificar drásticamente elementos del paisaje simbólico y práctico cotidiano, las nuevas autoridades proclaman que los paradigmas político-culturales han cambiado.

\section{El mensaje en la cultura histórica}

La piedra angular de la cultura histórica es, sin embargo, el mensaje, el discurso sobre el pasado. El estudio global de la cultura histórica debe incorporar los dos niveles que la conforman, tal como los ha definido Maria Grever: debe atender a su infraestructura (agentes y medios) y a sus contenidos (mensaje o discurso) ${ }^{47}$. Si entendemos la cultura histórica como un sistema socio-comunicativo de interpretación, transmisión y objetivación del pasado, es imprescindible estudiar lo que se está interpretando, transmitiendo y objetivando. Es decir, no hay que indagar sólo el cómo sino también el qué. Utilizando una metáfora gramatical, podría decirse que la cultura histórica es un sistema transitivo. Su sentido final (como en una frase transitiva) está subordinado al objeto directo, es decir, al contenido de la acción o del discurso.

En la cultura histórica se comunican interpretaciones del pasado; se intercambian y se difunden representaciones de la Historia a través de unos determinados medios. El análisis global de una cultura histórica debe plantearse qué visiones del pasado se intercambian y discuten y qué características tienen los

44. Cfr. Sánchez Marcos, Fernando, «En revenant sur les identités et les noms des rues en Espagne. Le cas de Barcelona», en Amalvi, C. (ed.), Une passion d'Histoire. Histoire(s), Mémoire(s) et l'Europe, Toulouse, 2002, pp. 339-349.

45. Stachel, Peter y Jaworski, Rudolf (eds.), Die Besetzung des öffentlichen Raumes. Politische Plätze, Denkmäler und Strassennamen im europäischen Vergleich, Leipzig, 2007, p. 28.

46. Cfr. Azaryahu, Maoz, «The Power of Commemorative Street Names».

47. Cfr. Grever, Maria, «The Gender olf Patrimonial Pride». 
discursos de memoria en juego. Utilizo el plural conscientemente. Ninguna cultura histórica está determinada por una única narrativa. Al haber múltiples creadores de discursos de memoria, hay multitud de intenciones y discursos, que a veces se oponen abiertamente. Algunas narrativas encuentran más eco en la opinión pública, mientras otras quedan reducidas a un pequeño grupo. La investigación de los discursos de memoria no debe solamente analizar, por tanto, sus contenidos, sino también atender a cómo interactúan y se relacionan entre ellos. Como ha señalado Wertsch, en muchas ocasiones las narrativas sólo se entienden cabalmente como respuesta o contrapunto a otras narrativas ${ }^{48}$. La cultura histórica de una sociedad tiene habitualmente una tensión dialógica y competitiva. Los discursos se refieren mutuamente y compiten por establecerse como dominantes ${ }^{49}$.

Debemos estudiar, por tanto, no sólo el texto, sino también el contexto. Este contexto está conformado, en buena medida, por la propia infraestructura de la cultura histórica (intenciones de los emisores, medios disponibles, posición de los receptores), pero también por las condiciones sociales y culturales en las que estos discursos emergen. Pero más allá, el análisis de los contenidos debe procurar encontrar la estructura narrativa básica que subyace a todo relato histórico. Zeruvabel sugiere que la mayoría de discursos sobre el pasado se articulan siguiendo alguno de los siete modelos histórico-narrativos principales: progreso, decadencia, círculo, zigzag, árboles, montañas-valles, legato-staccato ${ }^{50}$. Esta división es discutible, pero da una idea de lo que puede ser el estudio de los mo-

48. WertsCh, James, Voices of Collective Remembering..., pp. 87-93.

49. Cfr. Bodnar, John, Remaking America. Public Memory, Commemoration and Patriotism in the twentieth Century, Princeton University Press, 1994, p. 13.

50. Como se verá, Zeruvabel propone esta categorización atendiendo a varios parámetros, lo que provoca que en una misma narrativa pueda encontrarse más de un modelo narrativo. En el esquema «progresivo» se lee el proceso histórico como un avance imparable. En el «decadente» se considera la Historia como un progresivo alejamiento de la perfección de los orígenes. En el paradigma «circular», se prima la repetición de los procesos históricos. El modelo zigzag acentúa los puntos de inflexión en la Historia, tras los cuales se producen progresos o decadencias. Otras veces se interpreta la Historia como un conjunto de ramificaciones progresivas desde un primer tronco común (modelo «árbol»). Muchas veces, los relatos históricos presentan algunos períodos históricos como más densos («montañas») mientras omiten la atención en otros períodos que se entienden vacíos de acontecimientos («valles»). Finalmente, Zeruvabel distingue entre un modelo histórico continuista, donde las transiciones históricas son fruto de cambios progresivos («legato») y un modelo histórico que acentúa los cambios repentinos y bruscos («stachato»). Cfr. Zerubavel, Eviatar, Time Maps..., pp. 14-37. 
delos o esquemas que estructuran tanto las grandes teorías de la Historia como los relatos sobre períodos o acontecimientos limitados en el tiempo ${ }^{51}$.

\section{Los receptores de la cultura histórica}

Como en todas las esferas de la vida cultural de una comunidad, también en la cultura histórica hay personas o instituciones que tienen un papel especialmente activo (configuradores de la cultura histórica), mientras otras adquieren un rol principalmente pasivo (receptores). Lógicamente, esta distinción no es nítida ni absoluta. En el fondo, todos somos creadores y receptores de cultura histórica. Todos somos receptores porque hemos sido educados en una cultura histórica determinada y recibimos multitud de discursos de memoria que otros han difundido. Al mismo tiempo, todos somos configuradores porque, aunque sea en el ámbito de la familia o las amistades, relatamos algunas experiencias históricas y las objetivamos en fotografías, diarios o souvenirs. A nivel metodológico, sin embargo, es adecuada y válida la distinción entre configuradores y receptores de cultura histórica.

Los estudios sobre la memoria colectiva han tendido a primar la producción de la memoria sobre su recepción, identificando, de un modo algo arbitrario y simplón, las narrativas históricas propuestas por unas élites con las representaciones históricas (la conciencia histórica) de los ciudadanos ${ }^{52}$. Pero la experiencia social demuestra que, en muchas ocasiones, la interpretación que hace el receptor difiere notablemente de la intención del emisor. Mantengámonos en el ejemplo del nomenclátor urbano. Cuando Víctor Balaguer propuso el nombre de Muntaner para bautizar una arteria principal de Barcelona, pretendía honrar y perpetuar la memoria del mayor cronista medieval catalán. Sin embargo, ¿qué ciudadano actual de Barcelona piensa en el militar y escritor que participó en la campaña de Grecia cuando atraviesa la calle Muntaner? A la mayoría, el nombre de Muntaner les recuerda una estación de metro. Para otros, evocará un gimnasio, una discoteca o un atasco. En efecto, los lugares de memoria o los elementos conmemorativos son fácilmente reconocibles en el período en que se instauran. Es fácil, entonces, que la intención del emisor y la interpretación del receptor se asemejen. Pero con el paso del tiempo, se hace más y más difícil decodificar los

51. Jörn Rüsen y James Wertsch han trabajado también sobre los esquemas o «plantillas» fundamentales de los discursos históricos. Cfr. WertsCH, James, Voices of Collective Remembering...; Rüsen, Jorn, What is Historical Consciousness?... La obra pionera en el estudio de los recursos y la organización del relato histórico es, sin embargo, White, Hayden, Metahistory, Baltimore, 1973.

52. Kansteiner, Wulf, «Finding Meaning in Memory», p. 180. 
signos mnemónicos según su sentido original ${ }^{53}$. La significación primera empieza a erosionarse y se ve superada por nuevas lecturas y usos.

El estudio de la cultura histórica debe atender, pues, a los principios del triángulo hermenéutico, según el cual el significado de un texto o mensaje depende también de la interpretación del lector o receptor. Según Paul Ricoeur, «the sense of the significance of a narrative stems from the intersection of the world of the text and the world of the reader. The act of reading thus becomes the critical moment of the entire analysis» ${ }^{54}$.

\section{Conclusión}

Los estudios y la teorización de la memoria colectiva han abierto la puerta al análisis de un aspecto muy relevante de las mentalidades colectivas: los imaginarios históricos. En efecto, el análisis de la memoria colectiva ha permitido a historiadores y sociólogos comprender mejor los universos simbólicos que enmarcan la vida de todo grupo social y posibilitan su cohesión identitaria. La perspectiva de la «memoria colectiva» ha subrayado la relevancia de la memoria en la articulación de toda cultura y ha despertado un enorme interés por las diversas formas en que esta memoria social se ha plasmado y transmitido. Los académicos interesados en la vida de los grupos sociales han comprendido que la imagen que una sociedad tiene de sí misma, de su identidad presente y de su proyecto futuro, depende, en buena medida, de la representación que tiene de su pasado.

La categoría de memoria colectiva presenta, sin embargo, algunas dificultades conceptuales y metodológicas. La semántica del término centra su atención en los contenidos de memoria compartidos por los miembros de la comunidad pero excluye del marco de enfoque los procesos por los que estos contenidos se concretan. Por otro lado, el término memoria remite a un contenido de conciencia, quedando así algo relegadas sus manifestaciones y objetivaciones materiales (sus medios). No es fácil precisar hasta qué punto la memoria puede ser colectiva en un sentido literal y no metafórico y hasta qué punto son adecuadas las analogías psicoanalíticas con respecto a la memoria colectiva. Pero seguramente la mayor dificultad con la que topan los estudios sobre la memoria social es la habitual utilización política y mediática del término. Este uso ha convertido al concepto en un lugar común nebuloso y teñido de connotaciones políticas.

Propongo, por ello, una aproximación algo distinta a la memoria social, que entienda la memoria colectiva como un proceso dinámico de elaboración social

53. Bosrò, Vittoria y Kann, Christoph, (eds.), Geschichtsdarstellung. Medien, Methoden, Strategien, Wien, 2004, p. 158.

54. Ricoeur, Paul, «Life in Quest of Narrative», p. 26. 
de la experiencia histórica, en la que participan diversos agentes y medios y en la que se intercambian y «negocian» múltiples discursos sobre el pasado. En este artículo se ha sugerido el término de cultura histórica como un posible concepto que sintetiza el modo en que una sociedad se relaciona con su pasado. Más precisamente, la cultura histórica define el conjunto de recursos y prácticas sociales por las que los miembros de la sociedad interpretan, comunican, objetivan y utilizan su pasado. Puede decirse también que la cultura histórica es el sistema socio-comunicativo sobre el pasado en el que se forma la conciencia histórica de los miembros de la sociedad. La distinción metodológica entre los configuradores (emisores), los medios, los mensajes y los receptores que intervienen en este sistema socio-comunicativo permite indagar tanto la infraestructura como los contenidos de la cultura histórica. Se trata, por tanto, de una aproximación con un cariz algo más sociológico, que toma elementos de las ciencias de la comunicación. De todos modos, lo fundamental aquí no es el concepto utilizado sino la perspectiva propuesta. Algunos autores han adoptado esta metodología manteniendo el término habitual de «memoria colectiva» ${ }^{55}$.

Finalmente, cabe recordar que la cultura histórica tiene también su historia. En cuanto cultura, la relación de la sociedad con el pasado es plástica y se transforma al ritmo del tiempo y de los cambios sociales. La inmensa mayoría de los grupos humanos abordan su pasado. Pero cada uno lo hace de una manera peculiar y distintiva. Queda por delante el reto de determinar los trazos universales, si los hay, de la cultura histórica en época varias y culturas distintas. Los historiadores tenemos la tarea de historiar la cultura histórica y de precisar el modo en que los seres humanos nos hemos orientado en el tiempo a lo largo de los siglos. Las aportaciones de muchos historiadores pioneros espigadas a lo largo de este artículo pueden ofrecer herramientas útiles para seguir explorando y para continuar definiendo los contornos de una antropología de la experiencia histórica.

55. Cfr. Wertsch, James, Voices of Collective Remembering...; Kansteiner, Wulf, Finding Meaning in Memory.... 